\title{
Clinical course of infants with congenital heart disease who developed thyroid dysfunction within
} 100 days

Hye Jin Lee, $M D^{1}$, Hyeoh Won $\mathrm{Yu}, \mathrm{MD}^{2}$, Gi Beom Kim, MD, PhD², Choong Ho Shin, MD, PhD², Sei Won Yang, MD, PhD', Young Ah Lee, MD, PhD

${ }^{1}$ Department of Pediatrics, Hallym University Kangnam Sacred Heart Hospital, Seoul, ${ }^{2}$ Department of Pediatrics, Seoul National University Children's Hospital, Seoul, Korea
Received: 19 May, 2017

Revised: 19 June, 2017

Accepted: 17 August, 2017

Address for correspondence:

Young Ah Lee, MD, PhD

Department of Pediatrics, Seoul National University Children's Hospital, 103 Daehak-ro, Jongnogu, Seoul 110-799, Korea

Tel: $+82-2-2072-2082$

Fax: +82-2-2072-3917

E-mail:nina337@snu.ac.kr

https://orcid.org/0000-0001-91791247
Purpose: We investigated the clinical course of infants with congenital heart disease (CHD) who experienced thyroid dysfunction within 100 days of birth.

Methods: We performed retrospective medical reviews of $54 \mathrm{CHD}$ patients (24 male patients) who underwent a thyroid function test (TFT) between January 2007 and July 2016. Data were collected on birth history, diagnosis of CHD, underlying chromosomal or genetic abnormalities, medication history, surgery, ventilator care, and exposure to iodine contrast media (ICM). Results of neonatal screening tests (NSTs) and TFTs were reviewed.

Results: A total of 36 patients (29 transient, 7 permanent) showed thyroid dysfunction. Among the seven patients with permanent hypothyroidism, three had an underlying syndrome, three showed abnormal NST results, and one was admitted to the intensive care unit for macroglossia and feeding cyanosis. We found that infants with transient thyroid dysfunction had a lower birth weight and were more commonly exposed to thyroid disrupting medication and/or ICM. However, these risk factors were not significant. A total of 8 patients with a history of ICM exposure showed thyroid dysfunction. Excluding 3 patients with elevated thyroid stimulating hormone before ICM exposure, 5 patients recovered from transient thyroid dysfunction.

Conclusion: We observed thyroid dysfunction in two-thirds of CHD infants (53.7\% transient, $13.0 \%$ permanent) who had risk factors and received TFT screening within 100 days, despite normal NSTs. Further studies with larger sample sizes are required to revise the criteria for TFT screening in CHD infants.

Keywords: Thyroid function tests, Congenital, Heart, Infant, Hypothyroidism

\section{Introduction}

Congenital hypothyroidism is one of the most preventable causes of neurocognitive impairment because early treatment is possible in neonates ${ }^{1,2)}$. The thyroid hormone is important for normal growth and development in infancy ${ }^{3,4}$. After introducing national screening test (NST) using capillary thyroid stimulating hormone (TSH) level, the incidence of untreated congenital hypothyroidism has significantly decreased ${ }^{5)}$.

According to the Italian Registry of Congenital Hypothyroidism, congenital heart disease $(\mathrm{CHD})$ is the most frequent disease condition associated with congenital hypothyroidism ${ }^{6}$. $\mathrm{CHD}$ is also reported to be a risk factor for nonautoimmune hypothyroidism in children ${ }^{7}$. In addition, intravenous iodine contrast media (ICM) is frequently used for diagnostic imaging and therapeutic intervention in CHD patients. Excess iodine exposed by ICM may disturb thyroid function in adult and pediatric population ${ }^{8-11)}$. However, there is no generally accepted guideline for screening thyroid dysfunction in CHD infants. 
The 2014 European Society of Pediatric Endocrinology (ESPE) guideline recommends a second screening of thyroid function test (TFT) in neonates with the following high risk factors for hypothyroidism; preterm or low birth weight infants, critically ill infants who were admitted to intensive care unit (ICU), and monozygotic twins ${ }^{12)}$. Currently, secondary TFT screening in CHD infants is not different from that in those without CHD. Meanwhile, ICM exposure is not an absolute indication for TFT screening to detect thyroid dysfunction yet.

In this study, we aimed to identify frequency and clinical course of thyroid dysfunction in CHD infants who received TFT screening within 100 days according to current ESPE guidelines. We also aimed to identify the role of ICM exposure on developing thyroid dysfunction in CHD infants.

\section{Materials and methods}

\section{Subjects and methods}

The medical records of infants diagnosed with CHD between January, 2007 and July, 2016 at Seoul National University Children's Hospital were retrospectively reviewed. Those who had TFT results before 100 days of birth were included in this study. Early preterm infants (gestational age $[\mathrm{GA}]<34$ weeks), late preterm infants ( 34 weeks $\leq \mathrm{GA}<37$ weeks) with spontaneously closed patent foramen ovale or patent ductus arteriosus, infants whose mother had a history of autoimmune thyroid disease, and patients who expired before 3 years of age were excluded. A total of 54 infants (24 male infants) were finally included in this study.

Clinical data were collected on GA, birth weight, type of cardiac disease, other congenital anomalies, underlying chromosomal or genetic abnormalities, and previous history of medication affecting the thyroid function (dopamine, dobutamine, amiodarone, steroid, and furosemide), exposure to ICM through cardiac computed tomography (CT) or catheterization, operation, and mechanical ventilator care.

Laboratory findings of serum free thyroxine (fT4) and TSH levels from the first to last follow-up were reviewed. Serum concentrations of fT4 and TSH were measured using immunoradiometric kits (RIAKEY; Shin Jin Medics, Seoul, Korea). The normal ranges of serum $\mathrm{fT} 4$ and TSH are $0.70-1.80$ ng/dL (9.01-23.2 pmol/L) and 0.4-4.1 mIU/L, respectively. A capillary sample of blood was obtained from the heel to preform NST by chemiluminescent Immunoassay (Modular Analysis E 170 module, Roche, Germany). The cutoff values of TSH on NST were $<12 \mathrm{mIU} / \mathrm{L}$. NST results were also reviewed in infants who were transferred from outside hospital.

Patients were categorized into the 3 groups as follows; normal thyroid function, transient thyroid dysfunction, and permanent hypothyroidism. In infants who started levothyroxine medication, the dose, starting and ending dates of levothyroxine medication were reviewed. The transient thyroid dysfunction group included infants who showed transient hyperthyrotropinemia which spontaneously normalized or those who successfully discontinued levothyroxine during follow-up. Patients who failed to discontinue or withdraw levothyroxine medication till 3 years of age were categorized into permanent hypothyroidism.

\section{Statistical analysis}

Statistical analyses were performed using IBM SPSS Statistics ver. 24.0 (IBM Co., Armonk, NY, USA). Analysis for normality was performed first. All continuous variables were described as means \pm standard deviation. Binary logistic regression analysis was performed to investigate risk factors associated with transient thyroid dysfunction. A $P$-value of $<0.05$ was considered statistically significant.

\section{Ethics statement}

The present study was reviewed and approved by the Institutional Review Board of Seoul National University Hospital (approval number: 1702-021-829) and informed consent was waved.

\section{Results}

\section{Clinical characteristics of total subjects}

Table 1 shows the baseline characteristics of the total 54 infants. The mean age at initial TFT check-up was $32.2 \pm 27.7$ (range, 3-98) days after birth. Thirty-two patients (59.3\%) had NST results available and 6 of these patients had elevated TSH levels on their NST. The mean age at last follow-up was $5.3 \pm 2.9$ years. Eighteen patients $(33.3 \%)$ had normal thyroid function. Among 36 patients with thyroid dysfunction, 29 infants (53.7\%) had transient thyroid dysfunction, and 7 patients (13.0\%) had permanent hypothyroidism (Fig, 1, Table 1).

Thirteen patients $(24.1 \%)$ were late preterm (34 to 36 weeks of GA) and 11 patients (20.4\%) were small for GA. The CHDs of the patients were as follows; ventricular septal defect $(n=21)$,

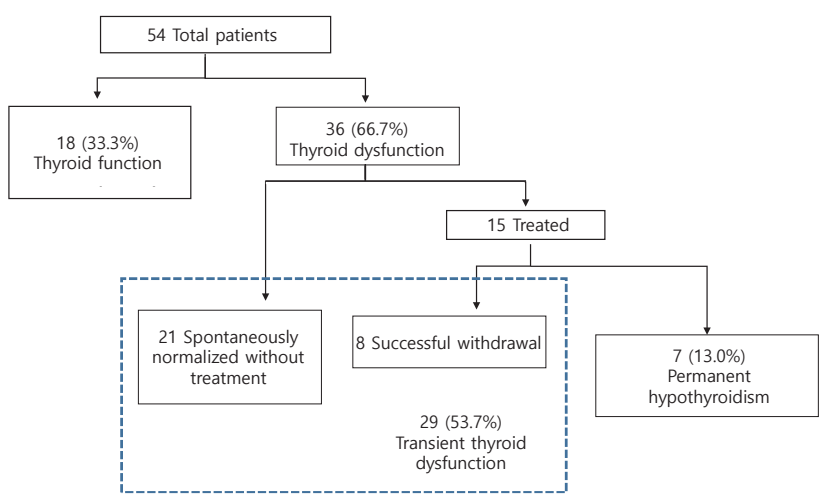

Fig. 1. Clinical course of total subjects. 
atrial septal defect $(n=15)$, atrioventricular septal defect $(n=1)$, tetralogy of Fallot $(n=6)$, pulmonary stenosis $(n=5)$, Ebstein anomaly $(n=2)$, functional single ventricle $(n=1)$, thoracic aorta widening $(n=1)$, mitral regurgitation $(n=1)$, and truncus arteriosus $(n=1)$. Twenty-three patients $(42.6 \%)$ were diagnosed with chromosomal anomaly or genetic syndrome as follows: Down syndrome $(n=11)$, other chromosomal defects $(n=2,46$, $\mathrm{XY}, \operatorname{del}(9)(\mathrm{p} 22)$, and 45, XX, -14, $\operatorname{der}(18), \mathrm{t}(14 ; 18)(\mathrm{q} 11.2 ; \mathrm{q} 23))$, Digeorge syndrome $(n=5)$, Williams syndrome $(n=3)$, BeckwithWiedemann syndrome $(n=1)$, and Alagille syndrome $(n=1)$. Before evaluation of TFTs, 5 infants $(9.3 \%)$ received cardiac surgery, 8 infants (14.8\%) had a history of ICM exposure, and 15 infants $(27.8 \%)$ had a history of thyroid disrupting medication such as dopamine, dobutamine, amiodarone, steroids, and/or furosemide (Table 1).

\section{Clinical characteristics of $\mathrm{CHD}$ patients with permanent hypothyroidism}

Among 7 patients categorized into the permanent hypothyroidism group (Table 2), 3 patients with Down syndrome ( $n=2$, cases 1 and 2$)$, and Williams syndrome $(n=1$, case 3) were included. Three of the remaining 4 patients without an underlying genetic syndrome were detected by elevated TSH levels on NST (cases 4-6). However, 1 patient (case 7, Table 2) was diagnosed with hypothyroidism 92 days after birth since delayed TSH elevation was detected in the ICU during the evaluation of feeding cyanosis and macroglossia.

Table 1. Characteristics of total subjects

\begin{tabular}{lcccc}
\hline Characteristic & Total & Normal & Transient thyroid dysfunction & Permanent hypothyroidism \\
\hline No. of patients & 54 & $18(33.3)$ & $29(53.7)$ & $7(13.0)$ \\
Male sex & $24(44.4)$ & $6(33.3)$ & $14(48.3)$ & $4(57.1)$ \\
Gestational age $(\mathrm{wk})$ & $37.8 \pm 1.7$ & $38.2 \pm 1.7$ & $37.6 \pm 1.8$ & $37.7 \pm 1.0$ \\
Birth weight $(\mathrm{kg})$ & $2.9 \pm 0.7$ & $3.1 \pm 0.6$ & $2.9 \pm 0.7$ & $2.5 \pm 0.5$ \\
Preterm & $13(24.1)$ & $3(16.7)$ & $9(31.0)$ & $1(14.3)$ \\
Small for gestational age & $11(20.4)$ & $2(11.1)$ & $7(24.1)$ & $2(28.6)$ \\
Chromosomal anomaly or genetic syndrome & $23(42.6)$ & $6(33.3)$ & $14(48.3)$ & $3(42.9)$ \\
Cyanotic heart disease & $17(31.5)$ & $6(33.3)$ & $5(27.6)$ & $3(42.9)$ \\
Ventilator care history & $8(14.8)$ & $3(16.7)$ & $3(10.3)$ & $1(14.3)$ \\
History of surgery & $5(9.3)$ & $1(5.6)$ & $5(17.2)$ & $1(14.3)$ \\
Exposure to iodine contrast media & $8(14.8)$ & $0(0)$ & $10(34.5)$ & $3(42.9)$ \\
Thyroid disrupting medication & $15(27.8)$ & $2(11.1)$ & & $3(42.9)$ \\
\hline
\end{tabular}

Values are presented as number (\%) or mean \pm standard deviation.

Table 2. Congenital heart disease infants with permanent hypothyroidism

\begin{tabular}{|c|c|c|c|c|c|c|c|c|c|c|c|c|}
\hline Case & Sex & $\begin{array}{l}\text { Congenital } \\
\text { heart disease }\end{array}$ & $\begin{array}{l}\text { Underlying } \\
\text { disease }\end{array}$ & $\begin{array}{c}\text { GA } \\
(w k)\end{array}$ & $\begin{array}{l}\text { Birth } \\
\text { weight } \\
\text { (kg) }\end{array}$ & $\begin{array}{c}\text { TSH } \\
\text { (NST) } \\
(\mathrm{mIU} / \mathrm{L})\end{array}$ & $\begin{array}{c}\text { Age at } \\
\text { detection of } \\
\text { elevated TSH } \\
\text { (day) }\end{array}$ & $\begin{array}{c}\text { Serum } \\
\text { fT4 } \\
\text { (ng/dL) }\end{array}$ & $\begin{array}{c}\text { Serum } \\
\text { TSH } \\
\text { (m/U/L) }\end{array}$ & $\begin{array}{c}\text { Age at } \\
\text { start } \\
\text { levothyroxine } \\
\text { (day) }\end{array}$ & $\begin{array}{l}\text { Imaging } \\
\text { study }\end{array}$ & $\begin{array}{c}\text { Age at } \\
\text { last } \\
\text { follow-up } \\
\text { (yr) }\end{array}$ \\
\hline 1 & $M$ & TOF & $\begin{array}{c}\text { Down } \\
\text { syndrome }\end{array}$ & 39 & 2.3 & $\begin{array}{c}\text { Normal } \\
(2.9)\end{array}$ & 26 & 1.7 & 8.9 & 628 & NA & 8.0 \\
\hline 2 & $\mathrm{~F}$ & AVSD, PDA & $\begin{array}{l}\text { Down } \\
\text { syndrome }\end{array}$ & 36 & 1.8 & $\begin{array}{c}\text { Normal } \\
(6.8)\end{array}$ & 7 & 1.9 & 8.2 & 21 & NA & 3.9 \\
\hline 3 & M & AS, PS & $\begin{array}{l}\text { Williams } \\
\text { syndrome }\end{array}$ & 38 & 2.6 & NA & 83 & 1.0 & 5.5 & 130 & NA & 9.2 \\
\hline 4 & $\mathrm{~F}$ & $\begin{array}{l}\text { Large VSD, } \\
\text { ASD, PDA }\end{array}$ & None & 38 & 2.2 & $\begin{array}{c}\text { Elevated } \\
(44.8)\end{array}$ & 17 & 0.65 & 100 & 18 & NA & 8.3 \\
\hline 5 & M & $\begin{array}{l}\text { Functional single } \\
\text { ventricle }\end{array}$ & None & 38 & 3.2 & $\begin{array}{c}\text { Elevated } \\
(14.5)\end{array}$ & 7 & 1.18 & 28.0 & 380 & NA & 3.7 \\
\hline 6 & $\mathrm{~F}$ & IAA, PDA,VSD & None & 37 & 2.6 & $\begin{array}{c}\text { Elevated } \\
\text { (157) }\end{array}$ & 17 & 0.10 & 801.0 & 17 & $\begin{array}{l}\text { Lingual } \\
\text { thyroid }\end{array}$ & 6.1 \\
\hline 7 & M & Large ASD & None & 38 & 3.0 & $\begin{array}{c}\text { Normal } \\
\text { (NA, } \\
\text { outside) }\end{array}$ & 92 & 0.89 & 22.3 & 92 & NA & 6.5 \\
\hline
\end{tabular}

Normal values of TSH (NST), serum fT4, and serum TSH were $\leq 12 \mathrm{mlU} / \mathrm{L}, 0.70-1.80 \mathrm{ng} / \mathrm{dL}$, and 0.4-4.1 mlU/L, respectively.

GA, gestational age; TSH, thyroid stimulating hormone; NST, neonatal screening test; fT4, free thyroxine; TOF, tetralogy of Fallot; AVSD, atrioventricular septal defect; PDA, patent ductus arteriosus; AS, aortic stenosis; PS, pulmonary stenosis; VSD, ventricular septal defect; ASD, atrial septal defect; IAA, interrupted aortic arch; NA, not available. 


\section{Factors associated with transient thyroid dysfunction in infants with $\mathrm{CHD}$}

Among 29 patients categorized into the transient thyroid dysfunction group, 8 patients initially started levothyroxine and successfully discontinued medication at a later follow-up. The remaining 21 patients showed transient hyperthyrotropinemia which was spontaneously normalized without medication (Fig. 1).

The transient thyroid dysfunction group $(\mathrm{n}=29)$ had higher proportions of patients with a chromosomal anomaly or genetic syndrome, preterm birth, small for GA, history of ICM exposure, and use of thyroid disrupting medication than the normal thyroid function group $(\mathrm{n}=18)$. However, none of aforementioned risk factors including ICM exposure was statistically significant as a result of binary logistic regression analysis (Supplementary Table 1).

\section{Clinical course of patients who had a history of ICM exposure}

A total of 8 patients who had a history of ICM exposure were categorized into permanent hypothyroidism $(n=3)$ or transient thyroid dysfunction ( $\mathrm{n}=5$, Table 3 ) group. Three patients with permanent hypothyroidism had already elevated levels of TSH before ICM exposure, suggesting congenital defects regardless of ICM exposure. When we closely looked at the 5 patients with transient thyroid dysfunction, we observed TSH levels increased 3 to 24 days after ICM exposure. Three of these 5 patients started levothyroxine medication and successfully discontinued before 3 years of age (cases 1,4, and 5; Table 3 ).

\section{Discussion}

The prevalence of vitamin D deficiency in pediatric patients Two-thirds of the 54 CHD infants who received TFT screening within 100 days according 2014 ESPE guideline showed thyroid dysfunction. Seven patients (13\%) were categorized into permanent hypothyroidism requiring persistent levothyroxine medication. Twenty-one infants (53.7\%) with transient thyroid dysfunction had lower birth weight, and had more exposure to ICM and/or thyroid disrupting medication than those with normal thyroid function; however, none of risk factors including ICM exposure were statistically significant in this study. Despite normal NST results, delayed TSH elevation was detected in critically ill patient with CHD during ICU care. Unless CHD infants had elevated TSH levels before ICM exposure, thyroid dysfunction was transient in this study.

Seven patients with permanent hypothyroidism received TFTs according to the 2014 ESPE guideline ${ }^{12)}$, since they had risk factors for thyroid dysfunction such as Down syndrome, Williams syndrome, low birth weight, and/or ICU admission. Despite normal results of NST, TFT needs to be evaluated if CHD infants had risk factors for thyroid dysfunction. This study supports the current guideline recommending second TFT screening in CHD infants who had known risk factors related to thyroid dysfunction.

Half of CHD infants (53.7\%) with risk factors showed transient thyroid dysfunction. Preterm birth and/or low birth weight ${ }^{13-15)}$, thyroid disrupting medication ${ }^{16-18)}$, and exposure to disinfectant containing iodine and/or $\mathrm{ICM}^{8-11,19-22)}$ were included as candidate risk factors for developing transient thyroid dysfunction in this study. Intrauterine stress with growth restriction and compensatory response to mild suppression of the thyroid gland ${ }^{23)}$, a significant reduction of the expression of thyroid receptor isoforms in the fetal brain with intrauterine

Table 3. Congenital heart disease infants with transient thyroid dysfunction after exposure to iodine contrast media (ICM)

\begin{tabular}{|c|c|c|c|c|c|c|c|c|c|c|c|}
\hline Case & Sex & $\begin{array}{c}\text { Congenital } \\
\text { heart disease }\end{array}$ & $\begin{array}{l}\text { Underlying } \\
\text { disease }\end{array}$ & $\begin{array}{l}\text { Birth } \\
\text { weight } \\
(\mathrm{kg})\end{array}$ & $\begin{array}{l}\text { TSH (NST) } \\
(\mathrm{mlU} / \mathrm{L})\end{array}$ & $\begin{array}{l}\text { Serum TSH } \\
\text { before } \\
\text { exposure } \\
\text { to ICM }\end{array}$ & $\begin{array}{l}\text { Exposure to } \\
\text { ICM (age [day] } \\
\text { at exposure) }\end{array}$ & $\begin{array}{c}\text { Serum TSH } \\
\text { after exposure } \\
\text { to ICM } \\
\text { (age [day] } \\
\text { at evaluation) }\end{array}$ & $\begin{array}{l}\text { Levothyroxine } \\
\text { medication } \\
\text { (dose, age [day] } \\
\text { at start) }\end{array}$ & $\begin{array}{l}\text { Levothyroxine } \\
\text { withdrawal } \\
\text { (age [day] } \\
\text { atdiscontinuation) }\end{array}$ & $\begin{array}{l}\text { Imaging } \\
\text { study }\end{array}$ \\
\hline 1 & $\mathrm{~F}$ & IAA, VSD, ASD & $\begin{array}{l}\text { Digeorge } \\
\text { syndrome }\end{array}$ & 2.5 & $\begin{array}{c}\text { Normal } \\
(9.5)\end{array}$ & 4.0 & $\begin{array}{c}\text { CT angiography } \\
\text { (13) }\end{array}$ & $23.04(25)$ & $\begin{array}{l}\text { Yes }(15.5 \mu \mathrm{g} / \\
\mathrm{kg} / \text { day at } 25)\end{array}$ & Yes (33) & NA \\
\hline 2 & $\mathrm{~F}$ & TOF & $\begin{array}{l}\text { Digeorge } \\
\text { syndrome }\end{array}$ & 2.9 & $\begin{array}{c}\text { Normal } \\
(7.6)\end{array}$ & NA & $\begin{array}{c}\text { CT angiography } \\
\text { (4) }\end{array}$ & $5.4(20)$ & No & - & NA \\
\hline 3 & M & VSD, MR, ASD & $\begin{array}{c}46, X Y, \operatorname{del}(9) \\
(p 22)\end{array}$ & 3.7 & NA & NA & $\begin{array}{c}\text { CT angiography } \\
(71)\end{array}$ & $5.3(74)$ & No & - & NA \\
\hline 4 & $\mathrm{~F}$ & $\begin{array}{l}\text { AP window, } \\
\text { ASD, VSD }\end{array}$ & None & 1.7 & $\begin{array}{c}\text { Normal } \\
(1.7)\end{array}$ & NA & $\begin{array}{c}\text { CT angiography } \\
\text { (6) }\end{array}$ & $13.7(30)$ & $\begin{array}{c}\text { Yes }(6.6 \mu \mathrm{g} / \mathrm{kg} / \\
\text { day, } 30)\end{array}$ & Yes (889) & Normal \\
\hline 5 & M & VSD, MAPCA & None & 2.3 & NA & 2.8 & $\begin{array}{c}\text { Cardiac } \\
\text { catheterization } \\
(417)\end{array}$ & $22.6(449)$ & $\begin{array}{c}\text { Yes }(3.8 \mu \mathrm{g} / \mathrm{kg} / \\
\text { day at } 449)\end{array}$ & Yes (894) & Normal \\
\hline
\end{tabular}

Normal values of TSH (NST), and serum TSH were $\leq 12 \mathrm{mIU} / \mathrm{L}$, and 0.4-4.1 $\mathrm{mlU} / \mathrm{L}$, respectively.

TSH, thyroid stimulating hormone; NST, neonatal screening test; IAA, interrupted aortic arch; VSD, ventricular septal defect; ASD, atrial septal defect; CT, computed tomography; TOF, tetralogy of Fallot; MR, mitral regurgitation; AP window, aortopulmonary windrow; MAPCA, major aortopulmonary collateral arteries; NA, not available. 
growth restriction and the resetting of TSH sensitivity ${ }^{24)}$ may affect thyroid function. Having a history of dopamine, dobutamine, furosemide, steroid ${ }^{16,17)}$ and amiodarone ${ }^{18)}$ was known to affect thyroid function. Meanwhile, diagnostic tools using ICM such as cardiac CT, and catheterization are being increasingly performed, especially for evaluation of cardiac structural anomaly. Thyroid dysfunction after ICM exposure has been reported in adults ${ }^{11,20)}$ and infants with $\mathrm{CHD}^{21,22)}$. However, none of candidate risk factors was statistically significant in our study.

Recently, three term CHD infant cases were reported, who developed iodine-induced hypothyroidism 5 to 11 days after exposure to ICM and/or disinfectant containing iodine ${ }^{19)}$, which emphasizes that the thyroid function needs to be evaluated after excess iodine exposure in CHD infants. Two of these 3 infants had transient hypothyroidism, and one had severe hypothyroidism requiring ongoing thyroid replacement in the aforementioned study ${ }^{19}$. Iodine induced hypothyroidism is explained by failure to escape the Wolff-Chaikoff effect ${ }^{10)}$. In healthy individuals, despite iodine excess, thyroid hormone homeostasis is maintained by the acute Wolff-Chaikoff effect by transient inhibition of thyroid hormone synthesis through decreased organification. Typically, the thyroid escapes from the acute Wolff-Chaikoff effect within a few days through down regulation of the sodium-iodine symporter in thyroid cells, and then normal thyroid hormone synthesis resumes ${ }^{10)}$. However, in CHD infants, the thyroid cannot escape the Wolff-Chaikoff effect, resulting in thyroid dysfunction ${ }^{19)}$. Although all CHD infants who had a history of ICM showed thyroid dysfunction at 3 to 24 days after exposure in our study, the independent pathogenic role of ICM exposure on thyroid dysfunction was not found. Except 3 patients who already had elevated TSH levels before ICM exposure, 5 patients successfully recovered from transient thyroid dysfunction.

This study is limited by a retrospective design and small sample size. Since infants at high risk for developing thyroid dysfunction selectively received TFTs in our study, we could not know the incidence of congenital hypothyroidism for the total CHD infants due to selection bias. Since the possibility of common mechanisms such as the pathologic role of $N K X 2.5$ or TBX1 coding sequences on the thyroid and heart development has been suggested ${ }^{25,26)}$, further study is needed to discover whether CHD itself is independently associated with congenital hypothyroidism.

In conclusion, thyroid dysfunction was detected in twothird of CHD infants who received TFT screening within 100 days according to current ESPE guidelines (53.7\% transient, $13.0 \%$ permanent), although NST results were normal. The independent effect of ICM exposure on thyroid dysfunction was not identified in this study. Further studies with larger sample sizes are required to revise criteria for TFT screening in CHD infants.

\section{Conflict of interest}

No potential conflict of interest relevant to this article was reported.

\section{Supplementary material}

Supplementary Table 1 can be found via https://doi. org/10.6065/apem.2017.22.4.253.

\section{References}

1. Grüters A, Krude H. Detection and treatment of congenital hypothyroidism. Nat Rev Endocrinol 2011;8:104-13.

2. Rastogi MV, LaFranchi SH. Congenital hypothyroidism. Orphanet J Rare Dis 2010;5:17.

3. Oerbeck B, Sundet K, Kase BF, Heyerdahl S. Congenital hypothyroidism: influence of disease severity and L-thyroxine treatment on intellectual, motor, and school-associated outcomes in young adults. Pediatrics 2003;112:923-30.

4. Léger J, Larroque B, Norton J; Association Française pour le Dépistage et la Prévetion des Handicaps de l'Enfant. Influence of severity of congenital hypothyroidism and adequacy of treatment on school achievement in young adolescents: a population-based cohort study. Acta Paediatr 2001;90:1249-56.

5. American Academy of Pediatrics, Rose SR; Section on Endocrinology and Committee on Genetics, American Thyroid Association, Brown RS; Public Health Committee, Lawson Wilkins Pediatric Endocrine Society, Foley T, et al. Update of newborn screening and therapy for congenital hypothyroidism. Pediatrics 2006;117:2290-303.

6. Olivieri A, Stazi MA, Mastroiacovo P, Fazzini C, Medda E, Spagnolo A, et al. A population-based study on the frequency of additional congenital malformations in infants with congenital hypothyroidism: data from the Italian Registry for Congenital Hypothyroidism (19911998). J Clin Endocrinol Metab 2002;87:557-62.

7. Passeri E, Frigerio M, De Filippis T, Valaperta R, Capelli $\mathrm{P}$, Costa E, et al. Increased risk for non-autoimmune hypothyroidism in young patients with congenital heart defects. J Clin Endocrinol Metab 2011;96:E1115-9.

8. Barr ML, Chiu HK, Li N, Yeh MW, Rhee CM, Casillas J, et al. Thyroid dysfunction in children exposed to iodinated contrast media. J Clin Endocrinol Metab 2016;101:236670 .

9. Ahmet A, Lawson ML, Babyn P, Tricco AC. Hypothyroidism in neonates post-iodinated contrast media: a systematic review. Acta Paediatr 2009;98:1568-74.

10. Lee SY, Rhee CM, Leung AM, Braverman LE, Brent GA, Pearce EN. A review: radiographic iodinated contrast media-induced thyroid dysfunction. J Clin Endocrinol Metab 2015;100:376-83. 
11. Rhee CM, Bhan I, Alexander EK, Brunelli SM. Association between iodinated contrast media exposure and incident hyperthyroidism and hypothyroidism. Arch Intern Med 2012;172:153-9.

12. Léger J, Olivieri A, Donaldson M, Torresani T, Krude H, van Vliet G, et al. European Society for Paediatric Endocrinology consensus guidelines on screening, diagnosis, and management of congenital hypothyroidism. J Clin Endocrinol Metab 2014;99:363-84.

13. Soto-Rivera CL, Fichorova RN, Allred EN, Van Marter LJ, Shah B, Martin CR, et al. The relationship between TSH and systemic inflammation in extremely preterm newborns. Endocrine 2015;48:595-602.

14. Mitchell ML, Hsu HW, Sahai I; Massachusetts Pediatric Endocrine Work Group. The increased incidence of congenital hypothyroidism: fact or fancy? Clin Endocrinol (Oxf) 2011;75:806-10.

15. Lee JH, Kim SW, Jeon GW, Sin JB. Thyroid dysfunction in very low birth weight preterm infants. Korean J Pediatr 2015;58:224-9.

16. Haugen BR. Drugs that suppress TSH or cause central hypothyroidism. Best Pract Res Clin Endocrinol Metab 2009;23:793-800.

17. Van den Berghe G, de Zegher F, Lauwers P. Dopamine suppresses pituitary function in infants and children. Crit Care Med 1994;22:1747-53.

18. Basaria S, Cooper DS. Amiodarone and the thyroid. Am J Med 2005;118:706-14.

19. Thaker VV, Leung AM, Braverman LE, Brown RS, Levine B. Iodine-induced hypothyroidism in full-term infants with congenital heart disease: more common than currently appreciated? J Clin Endocrinol Metab 2014;99:3521-6.

20. Gartner W, Weissel M. Do iodine-containing contrast media induce clinically relevant changes in thyroid function parameters of euthyroid patients within the first week? Thyroid 2004;14:521-4.

21. Linder N, Sela B, German B, Davidovitch N, Kuint J, Hegesh J, et al. Iodine and hypothyroidism in neonates with congenital heart disease. Arch Dis Child Fetal Neonatal Ed 1997;77:F239-40.

22. del Cerro Marín M, Fernández Ruiz A, García-Guereta L, Benito Bartolomé F, Burgueros M, Ares Segura S, et al. Thyroid function alterations in children with congenital cardiac disease after catheterization with iodinated contrast agents. Rev Esp Cardiol 2000;53:517-24.

23. Radetti G, Renzullo L, Gottardi E, D'Addato G, Messner H. Altered thyroid and adrenal function in children born at term and preterm, small for gestational age. J Clin Endocrinol Metab 2004;89:6320-4.

24. Kilby MD, Gittoes N, McCabe C, Verhaeg J, Franklyn JA. Expression of thyroid receptor isoforms in the human fetal central nervous system and the effects of intrauterine growth restriction. Clin Endocrinol (Oxf) 2000;53:469-77.

25. Dentice M, Cordeddu V, Rosica A, Ferrara AM, Santarpia $\mathrm{L}$, Salvatore D, et al. Missense mutation in the transcription factor NKX2-5: a novel molecular event in the pathogenesis of thyroid dysgenesis. J Clin Endocrinol Metab 2006;91: 1428-33.

26. van Engelen K, Mommersteeg MT, Baars MJ, Lam J, Ilgun A, van Trotsenburg AS, et al. The ambiguous role of NKX2-5 mutations in thyroid dysgenesis. PLoS One 2012; 7:e52685. 